\title{
How (and why) the immune system makes us sleep
}

\begin{abstract}
Luca Imeri* ${ }^{*}$ and Mark R. Opp ${ }^{\ddagger} \|$
Abstract | Good sleep is necessary for physical and mental health. For example, sleep loss impairs immune function, and sleep is altered during infection. Immune signalling molecules are present in the healthy brain, where they interact with neurochemical systems to contribute to the regulation of normal sleep. Animal studies have shown that interactions between immune signalling molecules (such as the cytokine interleukin 1) and brain neurochemical systems (such as the serotonin system) are amplified during infection, indicating that these interactions might underlie the changes in sleep that occur during infection. Why should the immune system cause us to sleep differently when we are sick? We propose that the alterations in sleep architecture during infection are exquisitely tailored to support the generation of fever, which in turn imparts survival value.
\end{abstract}

Modern sleep research began in 1953, with the discovery of rapid eye movement (REM) sleep and the realization that sleep is an active process that consists of two distinct phases. More than half a century of intense investigation has yet to provide an unequivocal answer to the question, 'Why do we sleep?' Nonetheless, we are beginning to understand the contribution of sleep to fundamental brain processes ${ }^{1,2}$.

In contrast to our lack of knowledge regarding the precise functions of sleep, we do know why we have an immune system. Living organisms are subject to constant attack by various pathogens, and the complex networks of physical and biochemical components that constitute the immune system keep the organism alive. Like sleep research, the field of immunology is a relatively young discipline. It should therefore not come as a surprise that systematic investigations of interactions between sleep and the immune system have only been conducted in the past 25 years (TIMELINE).

Although we briefly touch on the general role of sleep in health and disease, in this Review we focus on those areas of research that are most relevant to sleep as a component of the host defence against microbial pathogens. Links between the CNS and the peripheral immune system are now well established, and much is known about the mechanisms by which bidirectional communication occurs between these systems ${ }^{3}$. As a result of neuro-immune interactions, sleep loss alters immune function and immune challenges alter sleep. Thus, chronic sleep loss results in pathologies that are associated with increases in inflammatory mediators, and inflammatory mediators that are released during immune responses to infection alter CNS processes and behaviour, including sleep.

One class of immunomodulators, cytokines, has been extensively studied both with respect to host responses to infection and as regulators of physiological sleep. In this Review, we briefly summarize what is known about cytokines in the brain as regulators of normal, physiological sleep and what is known about their role in mediating the changes in sleep that are induced by infectious agents. We focus on one cytokine, interleukin 1 (IL-1), which, together with tumour necrosis factor (TNF), is the most investigated cytokine with respect to sleep. We then address the mechanisms by which IL-1 affects neurons and neurotransmitters involved in sleep regulation. Thus, the role of the serotonergic system in the regulation of sleep and as a mediator of IL-1's effects on sleep is reviewed. We conclude by proposing a hypothesis regarding the functional role of infection-induced alterations in sleep which suggests that the precise manner in which sleep is altered during infection facilitates the generation of fever and so promotes recovery.

\section{Sleep in health and disease}

Sleep is necessary for health. Although the brain gives us signals that indicate when we have had insufficient sleep, data show that more and more of us are ignoring these signals and reducing the amount of sleep we obtain each night. The percentage of adults who sleep less than $6 \mathrm{~h}$ 
Timeline | A brief history of cytokines and sleep

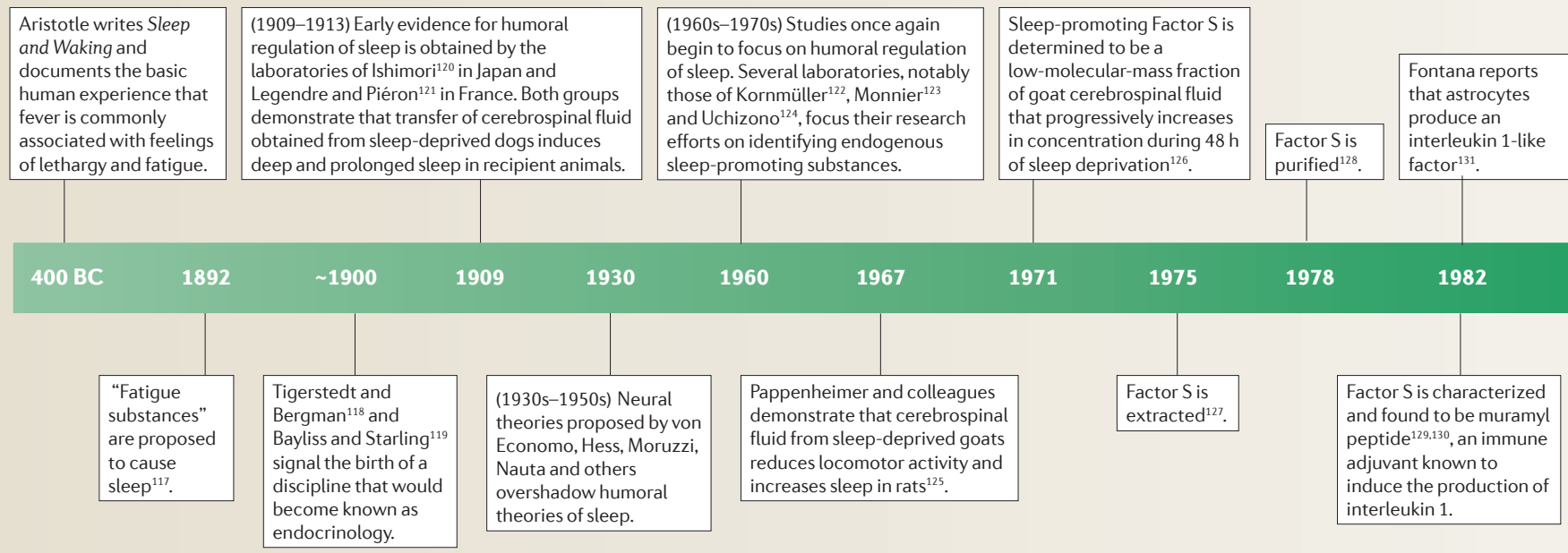

Encephalitis lethargica

An infectious process and an associated inflammatory response involving the brain and characterized by pronounced somnolence. The first cases were described in 1916 by the Viennese neurologist von Economo. The pathology is typical of viral infections and is localized principally to the midbrain, the subthalamus and the hypothalamus. The causative agent has not been definitively determined.

\section{Trypanosomiasis}

A disease caused by the protozoan Trypanosoma brucei and transmitted by several species of the tsetse fly. When the brain and meninges become involved, usually in the second year of infection, a chronic progressive neurologic syndrome results. Complete loss of the timing of sleep, alterations in sleep architecture, and later apathy, stupor and coma characterize the syndrome.

\section{Sleep fragmentation} Interruption of sleep bouts by brief arousals such that the duration of the bout is reduced and transitions from one behavioural state to another occur more frequently. per night is now greater than at any other time on record ${ }^{4}$. These survey data do not allow us to determine the extent to which the declining amounts of sleep are due to sleep disorders or to behavioural decisions, but it is clear that our current practice of sleeping less is largely driven by societal changes, including increased reliance on longer work hours and shift work, the trend for longer commute times, and increased accessibility to media of all sorts.

What are the consequences of sleep loss? Historically, it was widely thought that the only consequence of nighttime sleep loss was daytime sleepiness resulting in cognitive impairment. We now have compelling evidence that, in addition to cognitive impairment, sleep loss is associated with a wide range of detrimental consequences, with tremendous public-health ramifications. For example, short periods of sleep loss at the time of vaccination reduce the vaccine's effectiveness ${ }^{5,6}$. Sleep loss is associated with increased obesity ${ }^{7,8}$ and with reduced levels of leptin and increased levels of ghrelin ${ }^{8,9}$, the combination of which increases appetite. Sleep loss is also associated with diabetes and impaired glucose tolerance in a doserelated manner: individuals that report sleeping less than $6 \mathrm{~h}$ per night are $\sim 1.7$ times as likely, and those that report sleeping less than $5 \mathrm{~h}$ per night are $\sim 2.5$ times as likely, to have diabetes than individuals that obtain $7 \mathrm{~h}$ of sleep ${ }^{10}$. Cardiovascular disease and hypertension are also associated with sleep loss: the risk of a fatal heart attack increases $45 \%$ in individuals who chronically sleep $5 \mathrm{~h}$ per night or less ${ }^{11}$. Collectively, these examples demonstrate wideranging consequences of sleep loss on physical health. Obesity, diabetes and cardiovascular disease are pathologies that are characterized, in part, by inflammatory processes. The magnitude of the public-health burden imposed by these and other diseases underscores the importance of relationships between sleep and immune function and our efforts to understand them.

Sleep is disturbed during disease. We have all experienced the feelings of lethargy and fatigue associated with being sick. Some infections induce dramatic alterations in sleep. For example, recent cases of an encephalitis lethargica-like syndrome have been associated with streptococcal infections, during which severe sleep disruption occurs ${ }^{12}$. In addition, there is an extensive body of literature which demonstrates that the sleep of individuals infected with HIV is altered even before they show symptoms of AIDS ${ }^{13}$. Furthermore, infection with the parasite Trypanosoma brucei, the causative agent of human African trypanosomiasis (sleeping sickness), results in extreme fragmentation of sleep and a complete loss of the diurnal rhythms of sleep and wakefulness ${ }^{14,15}$. Although most people fortunately do not encounter these catastrophic infections, we have all suffered colds or 'the flu', and sleep is altered during these more common infections as well ${ }^{16,17}$.

\section{Cytokines and sleep}

Immune responses during infection include alterations in the concentrations and patterns of immune signalling molecules called cytokines. The list of cytokines and chemokines that have been studied in laboratory animals or human subjects and demonstrated to affect sleep is extensive and includes IL- $1 \alpha$, IL- $1 \beta$, IL-2, IL-4, IL-6, IL-8, IL-10, IL-13, IL-15, IL-18, TNFa, TNF $\beta$, interferon- $\alpha$ (IFN $\alpha)$, IFN- $\beta$, INF- $\gamma$ and macrophage inhibitory protein $1 \beta$ (also known as CCL4). Of these substances only two, IL-1 $\beta$ (hereafter referred to as IL-1) and TNFa (hereafter referred to as TNF), have been studied extensively enough to state that they are involved in the regulation of physiological (that is, spontaneous) sleep ${ }^{18-20}$. Evidence for a role for IL-1 and TNF in the regulation of physiological sleep has been derived from electrophysiological, biochemical and molecular genetic studies.

Cytokines participate in the regulation of sleep. Although most cytokines were first discovered in the peripheral immune system, several cytokines and their receptors have now been shown to be present in the $\mathrm{CNS}^{21-23}$. The CNS detects activation of the peripheral immune system 
An abstract presented at the annual meeting of the Federation of

American Societies for Experimental Biology ${ }^{132}$ reports sleep-inducing effects of interleukin 1 .

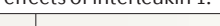

1983
(1985 onwards) Much is learnt

about the mechanisms and sites

of action whereby interleukin 1

and other cytokines regulate

sleep ${ }^{18}$.
1984

1985
1987

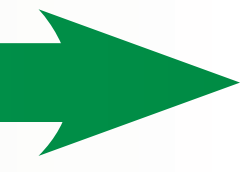

Two full-length papers demonstrate that central administration of interleukin 1 into rabbits or rats increases the amount of time spent in non-rapid eye movement sleep and alters the amplitude of the electroencephalogram waveform in the slow frequency bands ${ }^{133,134}$. ambient temperature ${ }^{34}$, both of which are associated with enhanced production of either IL-1 or TNF. Moreover, knockout mice that lack the type 1 IL-1 receptor, the type 1 TNF receptor or both ${ }^{35}$ spend less time in NREM sleep than control mice.

Administration of cytokines has been repeatedly shown to suppress REM sleep ${ }^{18}$, but antagonizing endogenous cytokines in healthy animals with receptor antagonists, soluble receptors or antibodies either has no effect on REM sleep or only slightly reduces it ${ }^{33,36,37}$. These observations suggest that cytokines modulate REM sleep during pathological conditions but do not contribute to the regulation of normal, physiological REM sleep. Moreover, recent demonstrations that alterations in REM sleep in mice lacking both IL-1 receptor 1 and TNF receptor 1 occur independently of changes in NREM sleep suggest that these cytokines influence REM sleep through mechanisms that differ from those that are involved in NREM-sleep regulation ${ }^{35}$.

Finally, the fact that diurnal rhythms of IL-1 and TNF levels vary with the sleep-wake cycle provides further evidence for the involvement of IL-1 and TNF in physiological sleep regulation ${ }^{18,20}$. In rats, IL- 1 and TNF mRNA and protein levels in the brain exhibit a diurnal rhythm with peaks that occur at light onset ${ }^{38}$; the light period in these rodents is the time when NREM sleep propensity is at a maximum. In humans, IL-1 plasma levels are highest at the onset of sleep ${ }^{39}$, and in cats cerebrospinal fluid IL-1 levels vary with the sleep-wake cycle ${ }^{40}$.

Cytokines mediate changes in sleep induced by infection. The data briefly reviewed above show that at least two pro-inflammatory cytokines are involved in regulating spontaneous, physiological NREM sleep. The question that then arises is whether these cytokines also mediate infection-induced alterations in sleep. Numerous systematic preclinical studies have demonstrated the extent to which infection alters sleep (reviewed in REFS 18,20,41). Although the precise alterations depend on the pathogen (bacteria, viruses, fungi or parasites), the host and the route of infection, at some time during the course of most infections there is an increase in the amount of time spent in NREM sleep and a decrease in the amount of REM sleep.

Models in which replicating pathogens are used to make animals sick are the most clinically relevant, but these types of studies are difficult to perform and interpret because the disease state develops over periods of days to weeks and the responsiveness to the infection can differ dramatically between animals. However, the changes induced in sleep by infectious agents are due to immune responses to biologically active structural components of the pathogen. Indeed, administration of such biologically active structural components results in changes in sleep that mimic those observed during infection with replicating pathogens. For this reason, most mechanistic studies of infection-induced alterations in sleep have used these structural components to induce the many facets of immune responses in the absence of replicating pathogens. The most commonly used are bacterial cell wall components such as 


\section{Lipid A}

The innermost, hydrophobic, lipid component of

lipopolysaccharide. Lipid A anchors the lipopolysaccharide to the outer membrane of the Gram-negative bacterial cell wall.

Lipopolysaccharide

A component (also known as endotoxin) of the outer wall of Gram-negative bacterial cell walls. It is composed of a lipid and polysaccharides joined by covalent bonds. It elicits strong immune responses through signalling pathways coupled to Toll-like receptor 4.

Muramyl dipeptide The synthetic analogue of muramyl peptides, the monomeric building blocks of bacterial cell wall peptidoglycan. Muramyl peptides are released by mammalian macrophages during the digestion of bacterial cell walls. lipid A, lipopolysaccharide and muramyl peptide (or the synthetic muramyl dipeptide). These bacterial cell wall components induce strong antigenic responses such as upregulation of pro-inflammatory cytokines, including IL- 1 and TNF ${ }^{42-44}$. When these bacterial cell wall components are administered to rabbits, rats, mice or humans (BOX 1), NREM sleep is increased and fragmented and REM sleep is suppressed ${ }^{45}$.

Of importance to this discussion, the effects of bacterial cell wall components on sleep are attenuated or blocked if cytokine systems are antagonized. For example, increases in NREM sleep after lipopolysaccharide or muramyl dipeptide administration are blocked if the IL-1 system is antagonized ${ }^{33,46}$. These data suggest that infection-induced alterations in sleep are mediated by cytokines such as IL-1 and TNF. They also show that administration of cytokines or pathogen components can serve as a model of infection-induced alterations in sleep. The advantages of such models are that responses occur on a timescale of hours rather than days or weeks, that many facets of immune and behavioural responses to infection are elicited, and that it is relatively easy to titrate the magnitude of the desired response.

\section{Serotonin and sleep}

Sleep, like any behaviour, is regulated in the brain by multiple overlapping neuroanatomic circuits and related neurochemical systems. IL-1 and TNF interact with several of these systems, including the serotonin (also known as 5 -hydroxytryptamine (5-HT)) system ${ }^{47}$. The 5 -HT system is one of the most investigated transmitter systems with respect to the regulation of sleep. In this section of the Review we briefly summarize the extensive body of literature that has demonstrated a role for the 5-HT system in regulating arousal states. Basic knowledge of 5-HT's complex role in sleep regulation is necessary before one can fully understand how interactions between the IL-1 and 5-HT systems contribute to the regulation of sleep.

Observations in 1955 (REF. 48) by Brodie and colleagues that brain 5-HT depletion by reserpine induces sedation prompted investigation of the role of 5-HT in the regulation of sleep-wake behaviour. 5-HT has since been shown to regulate multiple physiological processes and behaviours, including vigilance states, mood, food intake, thermoregulation, locomotion and sexual behaviour ${ }^{49}$. The importance of the 5 -HT system's role in sleep regulation is supported by both experimental data and clinical observations: pharmacological manipulations that affect the 5-HT system by altering neurotransmitter synthesis, release, binding or re-uptake and metabolism result in profound alterations in sleep ${ }^{50}$. Sleep is also altered during clinical conditions such as depression, in which the functionality of the 5-HT system is thought to be chronically altered ${ }^{51}$.

5-HT promotes arousal but is necessary for NREM sleep. The exact role of 5-HT in sleep regulation has been subject to debate $\mathrm{e}^{50,52}$. Data obtained in the $1960 \mathrm{~s}$ and early 1970s suggested that the 5 -HT system is necessary for NREM sleep: the destruction of raphe nuclei

\section{Box 1 Sleep and immunity in human volunteers}

There are some differences between laboratory animals and human subjects with respect to sleep-immune interactions. Most studies that use laboratory animals focus on the effects of host-defence activation on sleep and often include as outcome measures changes in immunomodulators in the brain. By contrast, the vast majority of studies that use human volunteers determine the effects of sleep loss on multiple facets of immunity, and immune-related outcome measures are almost always restricted to measures that can be obtained from whole blood, serum or plasma. The negative impact of sleep loss on public health is now recognized for pathologies that involve inflammatory processes, underscoring the importance of sleep to a healthy immune system.

It would be unethical to experimentally infect humans, but there are numerous clinical studies that describe the impact of HIV or trypanosome infection on sleep, all of which report that sleep is indeed altered. Healthy human volunteers under careful medical supervision have been subjected to host-defence activation by purified endotoxin ${ }^{101}$, an immune challenge in which there are no replicating pathogens. These studies show that humans are more sensitive to endotoxin than are laboratory animals; in humans, slow-wave sleep (the equivalent of non-rapid eye movement sleep in animals) is increased across the night by very low, subpyrogenic doses of endotoxin (less than one-thousandth of the per-bodyweight dose that elicits sleep responses in rats) ${ }^{102}$. As the endotoxin dose increases there are transient increases in slow-wave sleep, lasting approximately $1 \mathrm{~h}^{103}$. With even higher doses of endotoxin a much stronger host-defence response develops and, as in laboratory animals, sleep is severely disrupted ${ }^{102}$. This is probably due, in part, to increased activity of the hypothalamic-pituitary-adrenal axis, which induces wakefulness and promotes arousal ${ }^{104,105}$.

As mentioned above, in contrast to the few reports of the effect of host-defence activation by endotoxin in humans, there have been numerous systematic studies in which human volunteers have been deprived of sleep and effects on immunity determined. The first study of the effects of sleep loss on immunity in humans seems to be that of Palmblad et al. ${ }^{106}$. They demonstrated that $48 \mathrm{~h}$ of sleep deprivation reduced phytohaemagglutinin-induced DNA synthesis in lymphocytes, an effect that persisted for 5 days. This study was followed by more than 50 other studies that showed effects of sleep deprivation on the human immune system. By way of example, $64 \mathrm{~h}$ sleep deprivation is associated with alterations in many aspects of immunity, including leukocytosis, increased natural killer cell activity and increased counts of white blood cells, granulocytes and monocytes ${ }^{107}$. According to recent reports, as little as $4 \mathrm{~h}$ of sleep loss in a controlled laboratory setting increases the production of interleukin 6 and tumour necrosis factor by monocytes - an effect that, bioinformatic analyses suggest, is mediated by the nuclear factor- $\mathrm{kB}$ inflammatory signalling pathway ${ }^{108}$. The number and scope of studies of human sleep loss and immunity exceed that which can be summarized in this Review, and so for recent comprehensive reviews see REFS 19,109. 
(which contain the cell bodies of 5-HT neurons) or the depletion of brain 5-HT by administration of the 5-HT synthesis inhibitor $p$-chlorophenylalanine (PCPA) induces insomnia that is selectively reversed by the 5-HT precursor 5-hydroxytryptophan (5-HTP) ${ }^{50,52}$. However, data obtained from the mid 1970s onwards suggested that 5 -HT promotes wakefulness and suppresses NREM sleep. For instance, experimental

Anterior hypothalamus and preoptic area/basal forebrain

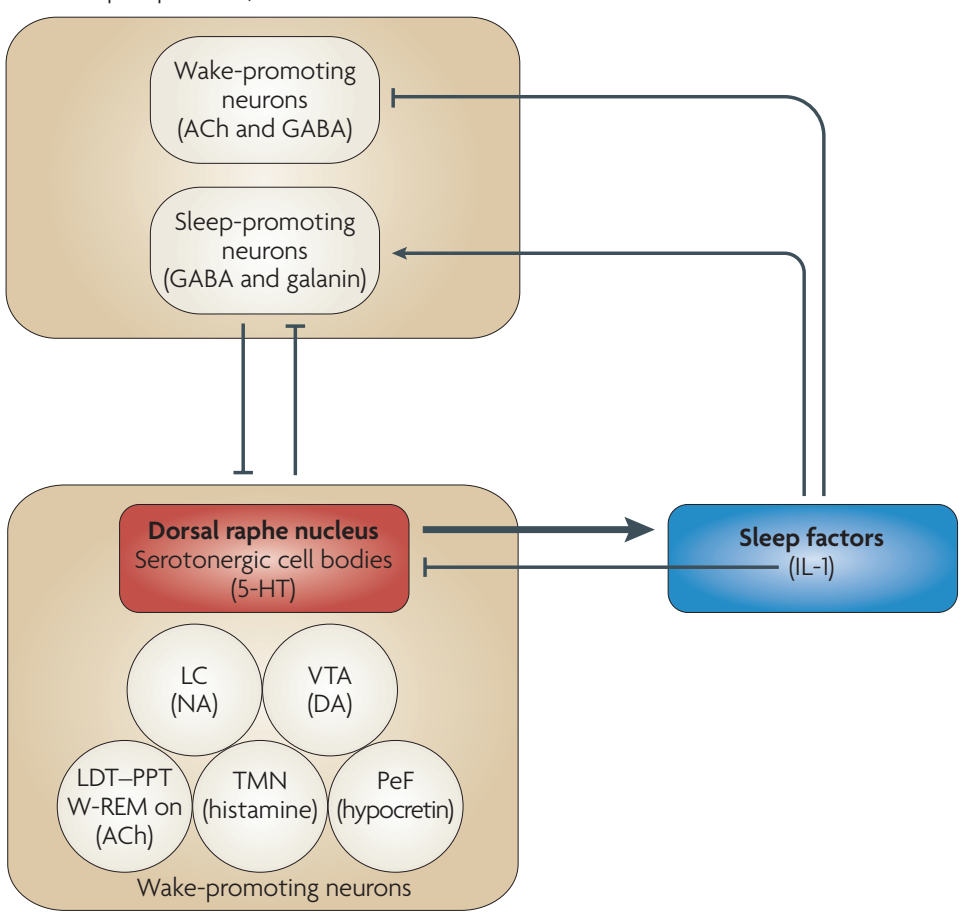

Brainstem and posterolateral hypothalamus
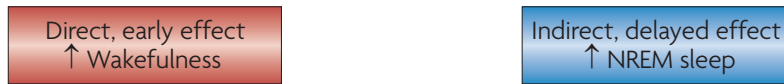

Figure 1 | Serotonin initially increases wakefulness and subsequently increases non-rapid eye movement sleep. Serotonergic neurons of the dorsal raphe nucleus, as well as other wake-promoting neurons located in the brainstem and the posterolateral hypothalamus, inhibit sleep-promoting neurons in the anterior hypothalamus, the preoptic area and the adjacent basal forebrain ${ }^{63,64}$. In turn, these rostral sleep-promoting neurons inhibit wake-promoting neurons in the brainstem and the posterolateral hypothalamus ${ }^{63,64}$. Serotonin (also known as 5-hydroxytryptamine (5-HT)) also induces the synthesis and/or release of sleep-promoting factors, which subsequently inhibit rostral wake-promoting neurons and activate rostral sleep-promoting neurons of the hypothalamus and basal forebrain. Interleukin 1 (IL-1) may be one of the 5 -HT-induced sleep factors because serotonergic activation induces IL-1 mRNA expression in the hypothalamus ${ }^{89}$ and IL-1 inhibits wake-promoting neurons in the hypothalamic preoptic area/basal forebrain ${ }^{82}$. IL-1 also inhibits wake-promoting serotonergic neurons in the dorsal raphe nucleus ${ }^{74,75}$. The schema is not intended to depict all interrelationships between the neuroanatomic regions and neurochemical systems involved in sleep regulation; rather, it is intended to illustrate the potential mechanisms by which 5-HT promotes wakefulness per se and at the same time stimulates the synthesis and/or release of sleep-promoting factors that then drive the sleep that naturally follows wakefulness ${ }^{52}$. ACh, acetylcholine; DA, dopamine; GABA, $\gamma$-aminobutyric acid; LC, locus coeruleus; LDT-PPT, laterodorsal and pedunculopontine tegmental nuclei; NA, noradrenaline; NREM, non-rapid eye movement; PeF, perifornical region; TMN, tuberomammillary nucleus; VTA, ventral tegmental area; W-REM on, neurons that are active during both wakefulness and rapid eye movement sleep. manipulations that increase the release and synaptic availability of 5-HT, such as electrical stimulation of the dorsal raphe nuclei (DRN), enhance wakefulness, whereas DRN inactivation enhances sleep ${ }^{53}$. In support of a wake-promoting role for 5-HT, a body of evidence has shown that the firing rates of serotonergic raphe neurons ${ }^{54-57}$ and 5-HT release ${ }^{58-61}$ are state-dependent: they peak during wakefulness and decrease during NREM sleep, and serotonergic cells become silent during REM sleep. In agreement with the interpretation that 5-HT is a wake-inducing substance, blockade of $5-\mathrm{HT}_{2}$ receptors increases NREM sleep in rats and humans ${ }^{62}$. (A more detailed discussion of the role of 5 -HT receptor subtypes in NREM-sleep regulation is beyond the scope of this Review.) 5-HT enhances wakefulness because serotonergic neurons in the DRN (together with other wake-promoting neurons, such as noradrenergic neurons in the brainstem locus coeruleus or hypocretinergic/orexinergic neurons in the hypothalamus) inhibit sleep-promoting neurons in the preoptic area, the anterior hypothalamus and the adjacent basal forebrain ${ }^{50,63}$ (FIG. 1). Noradrenergic and hypocretinergic/orexinergic wake-promoting neurons also stimulate each other's activity ${ }^{64}$.

An attempt to integrate and reconcile these apparently contradictory data led to the hypothesis that 5-HT promotes wakefulness through direct actions and also stimulates the synthesis and/or release of sleeppromoting factors ${ }^{52}$. Data now support this dual-role hypothesis for the involvement of 5-HT in the regulation of arousal states. The purported sleep-promoting factors induced by 5 -HT drive sleep by inhibiting wakepromoting neurons and stimulating sleep-promoting neurons (FIG. 1). Data obtained from rats and mice ${ }^{65-67}$ suggest that the role of 5-HT in the regulation of arousal states depends on the degree to which the 5-HT system is activated, the timing of the activation and the time that has passed since the activation (FIG. 1). When 5-HT release is enhanced in rats and mice through the administration of 5-HTP, the initial response is an increase in wakefulness and a reduction in NREM sleep ${ }^{65-67}$. This increase is fast, indicating that it is probably a direct effect of 5-HT. However, low doses of 5-HTP might not activate the 5-HT system sufficiently to stimulate sleep-inducing factors, a process that requires time. Following administration of higher physiological doses of 5-HTP, an increase in NREM sleep is apparent, after a delay, in both rats and mice ${ }^{65-67}$. This delayed increase in NREM sleep always occurs during the dark phase of the light-dark cycle, irrespective of the timing of 5-HTP administration ${ }^{65-67}$. Findings that 5-HTP administration increases the NREM sleep of rodents only during the dark phase suggest a fundamental property of the 5-HT system: the precise effects of serotonergic activation on sleep-wake behaviour depend not only on the extent but also on the timing of activation.

The data summarized above are in agreement with observations that acute administration in cats and rats of selective 5-HT re-uptake inhibitors first increases wakefulness and then increases NREM sleep ${ }^{50}$. The first studies of the relationship between 5-HT and sleep, carried 
out in the 1960s, were based on behavioural observations and did not include polygraphically defined determinations of vigilance states. Nevertheless, these studies reported biphasic responses to 5-HT administration in which behavioural 'activation' was followed by 'depression' (REF. 50).

Serotonin suppresses REM sleep. Serotonergic neurons in the raphe nuclei, like noradrenergic neurons in the locus coeruleus, are considered to be part of the systems that gate REM sleep by inhibiting the neurons that promote it ${ }^{68,69}$. In this view, suppressed serotonergic activity is permissive of REM-sleep generation, which is consistent with observations that pharmacological inhibition of the 5-HT system enhances REM sleep whereas increases in synaptic 5-HT availability inhibit it ${ }^{50}$. Accordingly, in rats and mice activation of the 5-HT system by administration of 5-HTP inhibits REM sleep, regardless of the dose and timing of administration ${ }^{65-67}$. The observation that mice that lack $5-\mathrm{HT}_{1 \mathrm{~A}}$ or $5-\mathrm{HT}_{1 \mathrm{~B}}$ receptor subtypes spend more time in REM sleep than control mice suggests that these receptor subtypes mediate the inhibitory effects of 5-HT on REM sleep ${ }^{70}$. Such a conclusion, supported by responses to pharmacological blockade of the same receptor subtypes ${ }^{70}$, of course does not rule out the possibility that 5-HT can also inhibit REM sleep by binding to other 5-HT receptor subtypes. At variance with the 'REM-off' role of 5-HT, observations that administration of a $5-\mathrm{HT}_{7}$ receptor antagonist inhibits REM sleep in rats $^{71}$ and that $5-\mathrm{HT}_{7}$ receptor-knockout mice spend less time in this sleep phase ${ }^{72}$ suggest that 5-HT might have a facilitatory (or permissive) role in REMsleep regulation through this specific receptor subtype. The role of $5-\mathrm{HT}_{2 \mathrm{~A}}$ or $5-\mathrm{HT}_{2 \mathrm{C}}$ receptors in REM-sleep regulation is more complex ${ }^{70}$.

\section{Interactions between IL-1 and 5-HT}

Evidence consistently demonstrates that IL-1 has a role in regulating physiological NREM sleep by acting, in part, through well-defined neuromodulatory systems. For example, IL-1 stimulates the synthesis and/or release of growth hormone-releasing hormone, prostaglandin $\mathrm{D}_{2}$, adenosine and nitric oxide. Each of these substances is implicated in regulating or modulating NREM sleep, and antagonizing these systems attenuates or blocks IL-1-induced increases in NREM sleep. For an extensive review of the role of neuromodulatory systems in mediating cytokine effects on sleep, see REF. 73.

In addition to acting on these neuromodulatory systems, IL- 1 acts directly on specific brain circuits and interacts with several neurotransmitters that have been implicated in regulating sleep. Thus, IL-1's effects on NREM sleep could be mediated by actions on several neurotransmitter systems, although systematic investigations of the interactions between IL-1 and neurotransmitter systems that are relevant to the regulation of sleep remain to be conducted (BOX 2). Here, we focus on the interactions between IL-1 and the 5-HT system because

\section{Box 2 | Effects of interleukin 1 on neurotransmitters involved in sleep regulation}

This Review focuses on interactions between interleukin 1 (IL-1) and the serotonergic system and, where relevant, on interactions between IL-1 and the GABA ( $\gamma$-aminobutyric acid)-ergic system. There are also some published reports of interactions between IL-1 and other neurotransmitter systems that are relevant to sleep regulation, and here we present a brief overview.

\section{Acetylcholine (ACh)}

Pontomesencephalic cholinergic neurons have a key role in rapid eye movement (REM) sleep generation and, together with basal forebrain cholinergic neurons, in cortical desynchronization and activation ${ }^{64,68}$. IL-1 inhibits ACh release in the hippocampus in vivo ${ }^{110}$, inhibits ACh synthesis in vitro in cultured pituitary cells ${ }^{111}$ and increases acetylcholinesterase activity and mRNA expression in neuron-glia co-cultures and in vivo in the rat cortex ${ }^{112}$. Suppression of REM sleep by IL-1 (REF. 18) may be mediated by inhibition of pontomesencephalic cholinergic neurons.

\section{Glutamate}

Glutamate is widely used in the CNS. For instance, it is released by the neurons that project from the brainstem reticular formation, which is part of the ascending arousal system ${ }^{64}$. Many anaesthetics attenuate glutamate-mediated neurotransmission ${ }^{64}$. Interactions between IL-1 and glutamatergic neurotransmission have been investigated at length because of the involvement of glutamate excitotoxicity in neuron loss during stroke or chronic neurodegenerative disease $^{113}$. Evidence suggests that IL-1 can potentiate or inhibit the effects of glutamate ${ }^{22,113}$. For instance, IL-1 decreases evoked glutamatergic excitatory responses in hippocampal CA1 pyramidal neurons ${ }^{81}$.

\section{Adenosine}

Adenosine, which is a by-product of energy metabolism, promotes sleep by inhibiting cholinergic and non-cholinergic wake-promoting neurons in the basal forebrain ${ }^{114}$. Because IL-1 stimulates adenosine production ${ }^{115,116}$, this effect can further contribute to IL-1-induced increases in non-REM sleep. Moreover, IL-1-induced inhibition of glutamatergic responses (at least in the hippocampus) is mediated by adenosine ${ }^{81}$.

\section{Monoamines}

Brainstem noradrenergic neurons of the locus coeruleus, dopaminergic neurons of the substantia nigra and ventral tegmental area and histaminergic neurons in the posterior hypothalamus are all wake-promoting ${ }^{64}$. IL- 1 activates these aminergic neurons and thereby enhances monoamine release in different brain areas ${ }^{47}$. Owing to their role in promoting wakefulness, IL-1-induced activation of aminergic neurons might counteract the increase in NREM sleep and thus maintain homeostasis. 


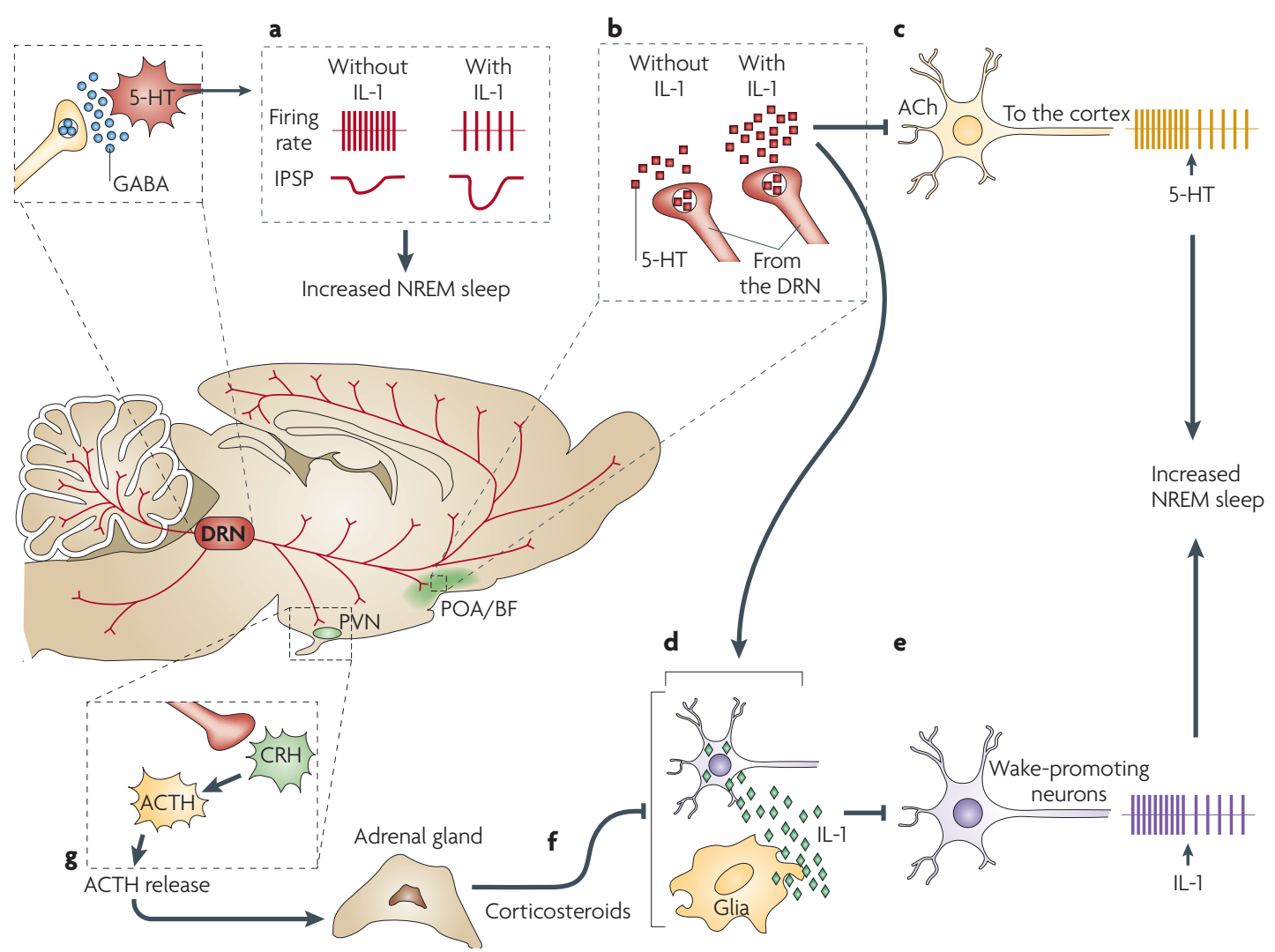

Figure 2 | Interleukin 1 and serotonin interact at multiple sites in the brain to regulate non-rapid eye movement sleep. A schematic representation of interactions in the brain among interleukin 1 (IL-1), serotonin (also known as 5-hydroxytryptamine (5-HT)) and $\gamma$-aminobutyric acid (GABA) that are relevant for the regulation of non-rapid eye movement (NREM) sleep. In the dorsal raphe nuclei (DRN), where IL-1 microinjections promote NREM sleep $^{74}$, IL-1 reduces the firing rate of wake-active serotonergic neurons by enhancing the inhibitory effects of $\mathrm{GABA}^{75}$ (a). In the hypothalamic preoptic area/basal forebrain region (POA/BF), IL-1 stimulates 5-HT release from axon terminals ${ }^{59}(\mathbf{b}) .5-\mathrm{HT}$, in turn, inhibits cholinergic neurons involved in cortical activation ${ }^{86}(\mathbf{c})$ and stimulates the synthesis of IL-1 (REF. 89) (d), which inhibits wake-promoting neurons (e) and activates a subset of sleep-promoting neurons in the $\mathrm{POA} / \mathrm{BF}^{82}$. IL-1 in the POA/BF is under potent inhibitory homeostatic control by corticosteroids ${ }^{92}(\mathbf{f})$ released into the blood by the adrenal cortex. Corticosteroid levels depend on the activity of the hypothalamicpituitary-adrenal axis ${ }^{92}$, which is stimulated by activation of the 5 -HT system ${ }^{89}(\mathbf{g})$. ACh, acetylcholine; ACTH, adrenocorticotropic hormone; $\mathrm{CRH}$, corticotropin-releasing hormone; IPSP, inhibitory postsynaptic potential; PVN, paraventricular nucleus of the hypothalamus.

Inhibitory postsynaptic potential

(IPSP). Hyperpolarization of the membrane potential of a postsynaptic neuron. IPSPs are induced by a neurotransmitter released by a presynaptic neuron. Hyperpolarization reduces neuronal excitability because it is more difficult to trigger an action potential in a hyperpolarized neuron. these are the interactions for which the most data have accumulated during the past 10 years. We review the evidence that IL-1 enhances NREM sleep in part through opposing but complementary actions on the 5-HT system in two distinct neuroanatomical regions, namely the DRN and the preoptic area of the hypothalamus, and the adjacent preoptic area and basal forebrain (POA/ $\mathrm{BF})$, which receives serotonergic innervation from the DRN. We show that IL-1 has inhibitory actions on the cell bodies of the wake-promoting DRN 5-HT system and increases 5-HT release from axon terminals in the POA/BF.

IL-1 actions in the DRN. IL-1 microinjection into the DRN of rats increases their NREM sleep ${ }^{74}$. In a brainstem slice preparation, bath application of IL-1 reduces the firing rates of DRN wake-promoting serotonergic neurons ${ }^{74,75}$ by enhancing GABA $(\gamma$-aminobutyric acid)-induced inhibitory postsynaptic potentials ${ }^{75}$ (FIG. 2a). Thus, IL-1 potentiates the physiological GABAergic inhibition that shapes the state-dependent discharge of DRN serotonergic neurons. IL-1 potentiates GABA signalling through multiple mechanisms: it recruits $\mathrm{GABA}_{\mathrm{A}}$ receptors to the cell surface ${ }^{76}$; it increases $\mathrm{Cl}^{-}$ uptake by acting on $\mathrm{GABA}_{\mathrm{A}}$ receptors ${ }^{77}$; and it induces a delayed potentiation of the $\mathrm{GABA}$-elicited $\mathrm{Cl}^{-}$current, an effect that is suppressed by the IL-1 receptor antagonist $^{76}$. The observation that IL-1 potentiates the effects of GABA in the DRN is in agreement with data which demonstrate that IL-1 enhances GABA-induced hyperpolarization and inhibition in other brain regions where IL- 1 acts both pre- and postsynaptically: IL-1 increases GABA release in anterior hypothalamic/preoptic area slice preparations ${ }^{78}$ and in brain explants ${ }^{79}$ and enhances GABAergic inhibitory postsynaptic potentials in hippocampal neurons ${ }^{80,81}$. 
$I L-1$ effects in the POA/BF. In the POA/BF, a brain area that is crucial for sleep regulation ${ }^{63,64}$, IL-1 directly inhibits wake-promoting neurons (FIG. 2e) and stimulates a subset of sleep-promoting neurons ${ }^{82}$. IL-1 also increases the number of c-FOS-immunoreactive neurons in the $\mathrm{POA} / \mathrm{BF}^{83}$. The number of these $\mathrm{c}-\mathrm{FOS}$ immunoreactive neurons positively correlates with the amount of NREM sleep during the $2 \mathrm{~h}$ before sacrifice, suggesting that the stained neurons were active during this sleep phase and thus might be sleep-active neurons. In addition, IL-1 stimulates 5 - $\mathrm{HT}$ release from axon terminals in the $\mathrm{POA}^{59}$ (FIG. 2b). IL-1 induces a tonic increase in 5-HT release but does not alter the state-dependent pattern of release - that is, the phasic increases in 5-HT release during wakefulness and the decreases during sleep are superimposed on the tonic IL-1-induced increase in 5-HT release ${ }^{59}$. The IL-1-induced enhancement of 5-HT release from axon terminals can result from local actions that are independent of the effects on serotonergic cell bodies in the DRN, because release from axon terminals is elicited by application of IL-1 directly into the hypothalamus ${ }^{84}$. The $\mathrm{POA} / \mathrm{BF}$ is the only brain area where increasing serotonergic activity by administering 5 -HTP restores physiological sleep in cats that have been made insomniac by PCPA administration ${ }^{85}$. 5-HT in the POA/BF might be essential for NREM sleep, because it hyperpolarizes and inhibits the cholinergic neurons that are responsible for cortical activation ${ }^{86}$ (FIG. 2c). The results of these studies suggest that IL-1 stimulates NREM sleep in part by enhancing axonal 5-HT release in the POA/ BF, where IL-1 and 5-HT inhibit wake-promoting neurons. 5-HT is essential for the effects of IL-1 on NREM sleep to fully manifest, because depletion of brain 5-HT by PCPA administration ${ }^{87}$ or blockade of $5-\mathrm{HT}_{2}$ receptors $^{88}$ transiently interferes with IL-1-induced increases in NREM sleep.

Not only does IL-1 induce 5-HT release and inhibit wake-promoting neurons in the hypothalamus, but reciprocal interactions between the 5-HT system and the IL-1 system are also of importance. Increasing serotonergic activation with 5-HTP induces IL-1 mRNA transcription in the hypothalamus ${ }^{89}$ (FIG. 2d) during periods when NREM sleep is enhanced by the same treatment ${ }^{65}$. There is specificity to this effect as 5-HTP does not alter IL-1 mRNA in the hippocampus or brainstem ${ }^{89}$. The 5-HTP-induced increase in IL-1 mRNA may be part of a self-sustaining regulatory loop, because IL-1 induces its own synthesis ${ }^{90,91}$. As a consequence, IL-1 can amplify the 5-HTP-induced increase in IL- 1 concentrations in the POA/BF, thus potentiating the inhibition of wake-promoting neurons in this region ${ }^{82}$ (FIG. 2e). Finally, IL-1 mRNA and protein are under potent homeostatic inhibitory control by the hypothalamic-pituitary-adrenal axis ${ }^{92}$ (FIG. 2f), the activity of which is increased by the activation of the 5 -HT system ${ }^{89}$ (FIG. 2g).

Collectively, the results of the studies reviewed suggest that the IL-1 and 5-HT systems engage in reciprocal interactions that contribute to the regulation of NREM sleep. In the POA/BF IL-1 enhances axonal 5-HT release and 5-HT stimulates the synthesis of IL-1, which inhibits wake-promoting neurons. IL-1 also inhibits wake-active serotonergic cell bodies in the DRN. Thus, IL-1 exerts opposite effects on serotonergic cell bodies and axon terminals. These effects complement each other and they both contribute to the same functional outcome: the enhancement of NREM sleep.

\section{Why is sleep altered during sickness?}

Sleep is clearly adaptive and much effort has been directed at determining its functions s $^{1,293,94}$. As we have reviewed, sleep is altered during infection. Infection increases the concentrations of cytokines, including IL-1, and the release of neurotransmitters, including 5-HT, in the brain, and interactions between IL-1 and 5-HT contribute to the regulation of sleep. We are beginning to understand how infection induces these changes, but it remains unknown why sleep is altered during sickness. We propose that altered sleep during infection, as a component of the acute-phase response and sickness behaviour, promotes recovery.

Is there any evidence to support the hypothesis that altered sleep during infection is a determinant of clinical outcome? Although it did not directly test this hypothesis, at least one study suggests that this might indeed be the case. Toth and colleagues ${ }^{95}$ retrospectively analysed data derived from long-term studies of bacterial or fungal infection-induced alterations in sleep in rabbits. The authors calculated for each animal a cumulative sleep-quality score that reflected both the duration and the intensity of NREM sleep. This approach allowed stratification of the outcome on the basis of whether the animals had high or low sleep-quality scores (good sleep or poor sleep, respectively) during the course of the infection. These cumulative sleep-quality scores were then correlated with the infective dose of the pathogen, multiple clinical parameters and the outcome. Analyses revealed that the infective dose of the pathogen differed between animals, and animals that received a higher pathogen dose generally had low cumulative sleep-quality scores. This suggests that the sicker the animal, the more disrupted its sleep. However, and of importance to this discussion, there were individual differences in the fates of animals that received the same infective dose: animals that survived had higher sleep-quality scores than animals that died. Although - as with any study that reports associations - this study did not demonstrate causality, and although it has yet to be repeated, these data are consistent with the hypothesis that dynamic changes in sleep during infection aid recovery.

How might infection-induced alterations in sleep promote recovery? We propose that they facilitate the generation of fever. In this view it is fever that imparts survival value, and fever could not develop during infection if sleep architecture was not altered. This hypothesis is based on two extensive bodies of literature, one describing links between sleep and thermoregulation ${ }^{96}$ and the other indicating that fever is adaptive ${ }^{97}$. 
a

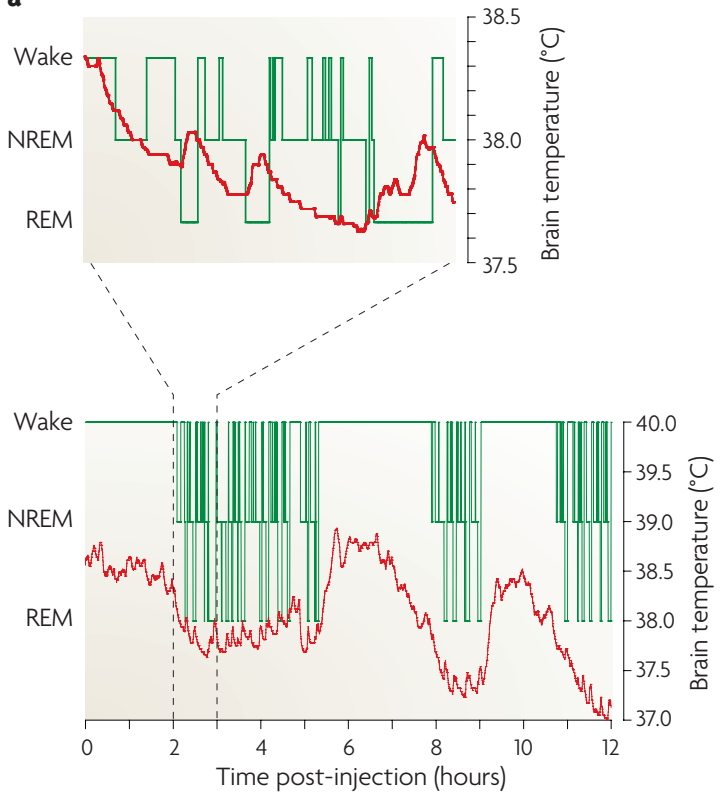

b

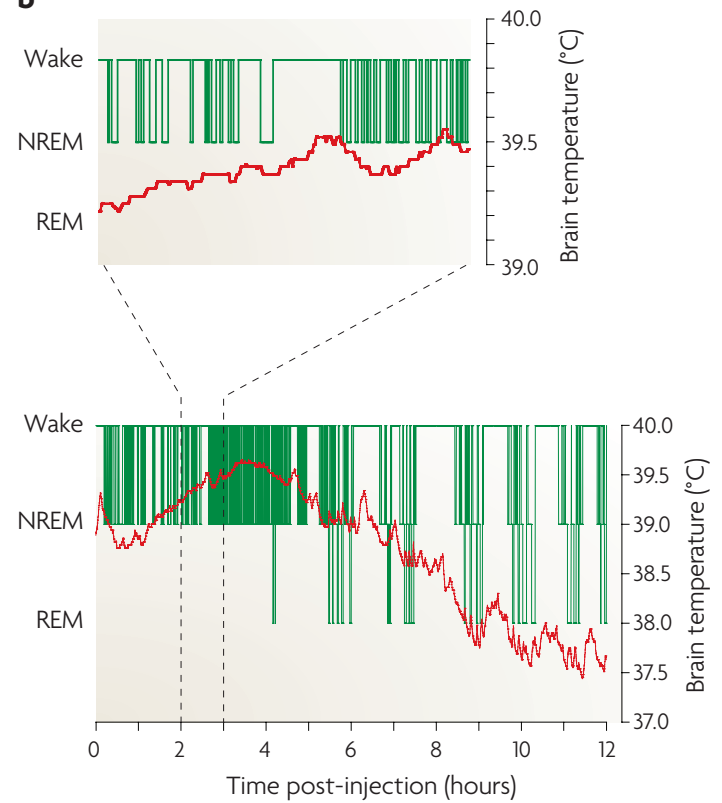

Figure 3 | Sleep architecture is altered during fever. The relationship between fever and changes in sleep architecture is apparent when interleukin $1(\mathrm{IL}-1)$ is administered to rats. a | A representative hypnogram depicting sleep-wake cycles of a male Sprague-Dawley rat demonstrates arousal state-dependent changes in brain temperature. Shown is a record of sleep-wake states (green line) and brain temperature (red line) for consecutive 12 s epochs recorded for $12 \mathrm{~h}$ after intracerebroventricular injection of vehicle. The injection was given at the beginning of the dark portion of the light-dark cycle. The expanded inset shows the arousal state-dependent changes in brain temperature that occur under normal conditions in a freely behaving rat. Brain temperature declines before entry into and during non-rapid eye movement (NREM) sleep, whereas it increases at the onset of and during REM sleep. Increases in brain temperature that are associated with wakefulness (wake) are of greater magnitude than those that occur during REM sleep. b | After intracerebroventricular injection of 5.0 ng IL-1 into the same rat as in part a, NREM sleep is fragmented, REM sleep is abolished (green line) and fever ensues (red line). The expanded inset shows the extent to which NREM sleep is fragmented during fever. This inset depicts the effects of IL-1 on sleep during the third post-injection hour, the same period presented in the expanded inset of part $\mathbf{a}$. In this animal, the effects of IL-1 on NREM sleep and REM sleep are apparent for almost $6 \mathrm{~h}$. Once NREM-REM sleep cycles reappear, arousal state-dependent changes become apparent and brain temperature subsides to control values.

The regulation of body temperature is coupled to sleep ${ }^{96}$ : superimposed on the circadian rhythm of body and brain temperature are arousal state-dependent temperature changes (FIG. 3a). For example, brain and body temperature decrease during NREM sleep; the longer and more consolidated the NREM-sleep episode, the greater the decrease in brain or body temperature, until the regulated asymptote is reached. By contrast, brain temperature increases rapidly during REM sleep ${ }^{96,98}$ (FIG. 3a). In addition, thermoregulation is dependent on the sleep-wake state; for example, shivering does not occur during REM sleep ${ }^{96,99}$.

Vertebrates and invertebrates develop fever in response to administration of pyrogens (fever inducers) or infection with pathogens. Data demonstrate increased survival when the host develops a moderate fever during bacterial or viral infections $s^{97}$. The survival value of fever to the host organism is conferred primarily by two mechanisms: facets of immune responses are potentiated at elevated body temperature, and the host environment is directly altered such that conditions for replication of the pathogen become less optimal ${ }^{97,100}$ (FIG. 4).
However, fever is energetically demanding: metabolism must be increased to raise and then maintain body temperature. It has been estimated that the mean increase in metabolism is $13 \%$ for every $1{ }^{\circ} \mathrm{C}$ increase in body temperature ${ }^{100}$. Increasing the amount of time spent in NREM sleep reduces the energy expenditure that is associated with competing activities, such as locomotion. But the changes in sleep architecture that occur during infection (suppressed REM sleep and increased but more fragmented NREM sleep) might have additional, feverpromoting benefits: shivering is crucial to the generation of fever but does not occur during REM sleep ${ }^{96}$. Perhaps for this reason REM sleep is eliminated during the early stages of fever (FIG. 3b). Furthermore, thermoregulatory mechanisms that reduce heat loss complement those involved in heat production (shivering) in the effort to increase body temperature. As heat dissipation normally occurs during NREM sleep, the fragmented nature of NREM sleep during the febrile response (FIG. 3b) may be viewed as a mechanism to reduce heat loss.

Data demonstrate that fever is adaptive and has evolved to increase survival in response to infection. 


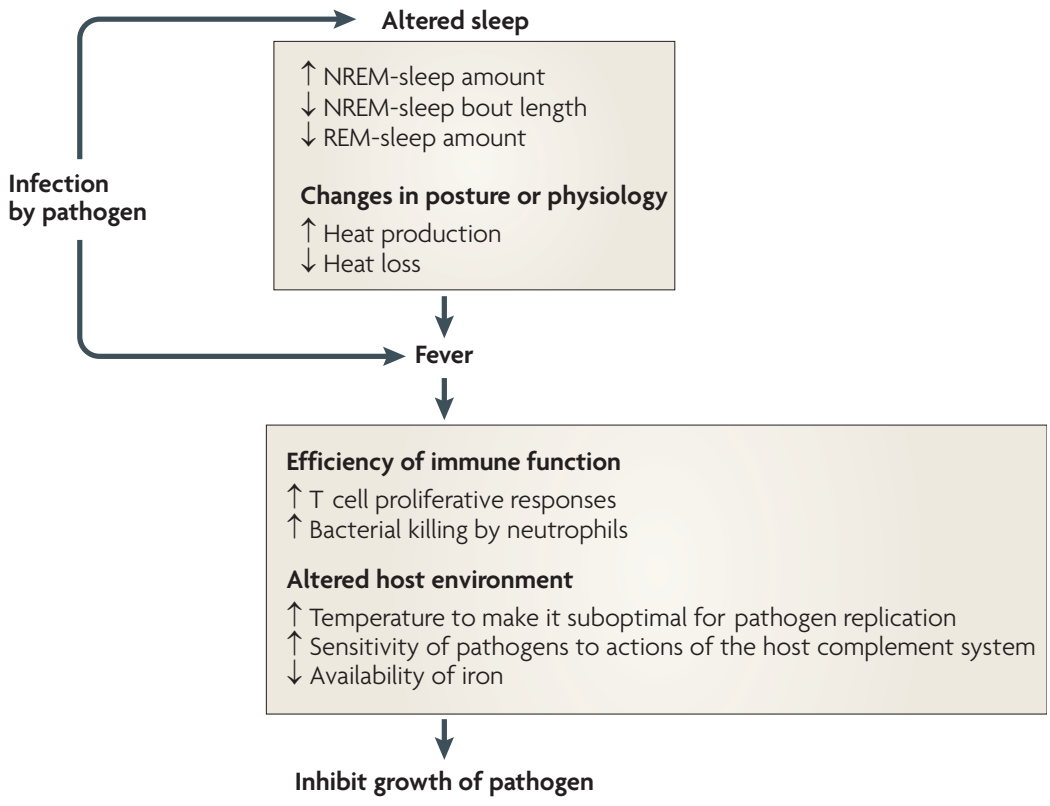

Figure 4 | Proposed principles by which changes in sleep architecture promote recovery from infection. Infection-induced alterations in sleep are such that increases in non-rapid eye movement (NREM) sleep provide energy savings, and short NREM-sleep bouts reduce heat loss. The reduction in REM sleep allows the animal to shiver. The combined changes in NREM and REM sleep facilitate the production of fever. Fever imparts survival value because it increases the efficiency of many facets of immune function and alters the host environment to make it less favourable for pathogen reproduction ${ }^{97}$.

Although it is unlikely that sleep has evolved solely to support the generation of fever during infection, the alterations in sleep in response to microbial pathogens are exquisitely designed to fulfil this role: the increase in NREM sleep conserves energy; the suppression of REM sleep allows shivering and, therefore, the production of fever; and the fragmentation of NREM sleep reduces heat loss.

\section{Conclusions and future directions}

Sleep is necessary for health as its loss or restriction is associated with multiple detrimental consequences. Although the interactions with neurotransmitters and neuromodulators through which cytokines enhance NREM sleep have been investigated at length, direct actions of cytokines on neurons in brain regions involved in the regulation of this sleep phase have only recently been determined. At present we know little about the mechanisms by which cytokines inhibit REM sleep. Investigating these mechanisms is important because REM sleep is disrupted in many pathologies that involve altered cytokine concentrations. For example, disturbed REM sleep and cytokine dysregulation are characteristic of major depression ${ }^{3}$. In addition to elucidating the mechanisms by which cytokines contribute to the regulation of the amount, pattern and distribution of sleep, crucial functional questions also wait to be answered. More systematic studies are required before we can understand the nature of cytokine involvement in altered sleep during sickness. Also of importance is the question of the extent to which alterations in sleep during sickness contribute to clinical outcome. Do alterations in sleep during infection contribute to survival as we propose and as is suggested by correlations between sleep quality and survival of infected rabbits ${ }^{95}$ ? Would recovery be facilitated if patients in hospitals were able to sleep better? Further investigation is required to better assess the mechanistic and functional relationships between sleep and morbidity and mortality, and to determine whether altered sleep promotes recovery.
1. Tononi, G. \& Cirelli, C. Sleep and synaptic homeostasis: a hypothesis. Brain Res. Bull. 62 143-150 (2003)

2. Krueger, J. M. et al. Sleep as a fundamental property of neuronal assemblies. Nature Rev. Neurosci. 9 , 910-919 (2008)

3 Dantzer, R O'Connor, J C. Freund G G Johnson, R. W. \& Kelley, K. W. From inflammation to sickness and depression: when the immune system subjugates the brain. Nature Rev. Neurosci. 9, 46-56 (2008).

4. Centers for Disease Control and Prevention. Percentage of adults who reported an average of $\leq 6$ hours of sleep per 24-hour period, by sex and age group-United States 1985 and 2004. MMWR Morb. Mortal. Wkly Rep. 54, 933 (2005).

5. Spiegel, K., Sheridan, J. F. \& Van Cauter, E. Effect of sleep deprivation on response to immunization. JAMA 288, 1471-1472 (2002).

6. Lange, T., Perras, B., Fehm, H. L. \& Born, J. Sleep enhances the human antibody response to hepatitis $A$ vaccination. Psychosom. Med. 65, 831-835 (2003).

7. Hasler, G. et al. The association between short sleep duration and obesity in young adults: a 13-year prospective study. Sleep 27, 661-666 (2004).

8. Taheri, S., Lin, L., Austin, D., Young, T. \& Mignot, E. Short sleep duration is associated with reduced leptin, elevated ghrelin, and increased body mass index. PLoS Med. 1, e62 (2004).

9. Spiegel, K., Tasali, E., Penev, P. \& Van Cauter, E. Brief communication: Sleep curtailment in healthy young men is associated with decreased leptin levels, elevated ghrelin levels, and increased hunger and appetite. Ann. Intern. Med. 141, 846-850 (2004).
10. Gottlieb, D. J. et al. Association of sleep time with diabetes mellitus and impaired glucose tolerance. Arch. Intern. Med. 165, 863-867 (2005).

11. Ayas, N. T. et al. A prospective study of sleep duration and coronary heart disease in women. Arch. Intern. Med. 163, 205-209 (2003).

12. Dale, R. C. et al. Encephalitis lethargica syndrome: 20 new cases and evidence of basal ganglia autoimmunity. Brain 127, 21-33 (2004).

13. Norman, S. E., Chediak, A. D., Kiel, M. \& Cohn, M. A. Sleep disturbances in HIV infected homosexual men. AIDS 4, 775-781 (1990).

14. Buguet, A et al. The duality of sleeping sickness: focusing on sleep. Sleep Med. Rev. 5, 139-153 (2001)

15. Lundkvist, G. B., Kristensson, K. \& Bentivoglio, M Why trypanosomes cause sleeping sickness. Physiology (Bethesda) 19, 198-206 (2004).

16. Drake, C. L. et al. Effects of an experimentally induced rhinovirus cold on sleep, performance, and daytime alertness. Physiol. Behav. 71, 75-81 (2000).

17. Bettis, R. et al. Impact of influenza treatment with oseltamivir on health, sleep and daily activities of otherwise healthy adults and adolescents. Clin. Drug Investig. 26, 329-340 (2006).

18. Opp, M. R. Cytokines and sleep. Sleep Med. Rev. 9 , 355-364 (2005)

19. Opp, M., Born, J. \& Irwin, M. in Psychoneuroimmunology (ed. Ader, R.) 579-618 (Burlington, Massachusetts, Elsevier Academic Press, 2007).

20. Krueger, J. M., Obal, F. J., Fang, J., Kubota, T. \& Taishi, P. The role of cytokines in physiological sleep regulation. Ann. NY Acad. Sci. 933, 211-221 (2001).
21. Eriksson, C., Nobel, S., Winblad, B. \& Schultzberg, M. Expression of interleukin $1 \alpha$ and $\beta$, and interleukin 1 receptor antagonist mRNA in the rat central nervous system after peripheral administration of lipopolysaccharides. Cytokine 12, 423-431 (2000)

22. Allan, S. M. \& Rothwell, N. J. Cytokines and acute neurodegeneration. Nature Rev. Neurosci. 2 734-744 (2001)

23. Garden, G. A. \& Moller, T. Microglia biology in health and disease. J. Neuroimmune Pharmacol. 1 , 127-137 (2006)

24 Breder C. D Dinarello, C. A \& Saper, C. B. Interleukin-1 immunoreactive innervation of the human hypothalamus. Science 240, 321-324 (1988). The first demonstration that neurons contain IL-1.

25. Marz, P. et al. Sympathetic neurons can produce and respond to interleukin 6. Proc. Natl Acad. Sci. USA 95, 3251-3256 (1998)

26. Ignatowski, T. A. et al. Neuronal-associated tumo necrosis factor (TNF $\alpha$ ): its role in noradrenergic functioning and modification of its expression following antidepressant drug administration. J. Neuroimmunol. 79, 84-90 (1997).

27. Breder, C. D., Tsujimoto, M., Terano, Y., Scott, D. W. \& Saper, C. B. Distribution and characterization of tumo necrosis factor-alpha-like immunoreactivity in the murine central nervous system. J. Comp. Neurol. 337 543-567 (1993)

28. Bette, M., Kaut, O., Schafer, M. K. \& Weihe, E. Constitutive expression of p55TNFR mRNA and mitogen-specific up-regulation of TNF $\alpha$ and p75TNFR mRNA in mouse brain. J. Comp. Neurol. 465 , 417-430 (2003). 
29. Ban, E. M. Interleukin-1 receptors in the brain: characterization by quantitative in situ autoradiography. Immunomethods 5, 31-40 (1994).

30. Olivadoti, M. D. \& Opp, M. R. Effects of i.c.v. administration of interleukin- 1 on sleep and body temperature of interleukin-6-deficient mice. Neuroscience 153, 338-348 (2008).

31. Opp, M. R., Obál, F. \& Krueger, J. M. Interleukin-1 alters rat sleep: temporal and dose-related effects. Am. J. Physiol. 260, R52-R58 (1991).

32. Lancel, M., Mathias, S., Faulhaber, J. \& Schiffelholz, T. Effect of interleukin-1 $\beta$ on EEG power density during sleep depends on circadian phase. Am. J. Physiol. 270, R830-R837 (1996).

33. Imeri, L., Bianchi, S. \& Opp, M. R. Inhibition of caspase-1 in rat brain reduces spontaneous nonrapid eye movement sleep and nonrapid eye movement sleep enhancement induced by lipopolysaccharide. Am. J. Physiol. 291, R197-R204 (2006).

This report that NREM sleep is reduced when cleavage of biologically active IL-1 from its inactive precursor is impeded provides additional evidence of a role for IL-1 in regulating physiological NREM sleep and in the alterations in NREM sleep that follow host defence activation.

34. Takahashi, S. \& Krueger, J. M. Inhibition of tumor necrosis factor prevents warming-induced sleep responses in rabbits. Am. J. Physiol. 272, R1325-R1329 (1997).

35 Baracchi, F. \& Opp, M. R. Sleep-wake behavior and responses to sleep deprivation of mice lacking both interleukin- $1 \beta$ receptor 1 and tumor necrosis factor- $\alpha$ receptor 1. Brain Behav. Immun. 22, 982-993 (2008).

36. Opp, M. R. \& Krueger, J. M. Anti-interleukin-1 $\beta$ reduces sleep and sleep rebound after sleep deprivation in rats. Am. J. Physiol. 266, R688-R695 (1994).

37. Opp, M. R. \& Krueger, J. M. Interleukin 1-receptor antagonist blocks interleukin 1-induced sleep and fever. Am. J. Physiol. 260, R453-R457 (1991).

38. Cearley, C., Churchill, L. \& Krueger, J. M. Time of day differences in IL $1 \beta$ and TNF $\alpha$ mRNA levels in specific regions of the rat brain. Neurosci. Lett. 352, 61-63 (2003).

39. Moldofsky, H., Lue, F. A., Eisen, J., Keystone, E. \& Gorczynski, R. M. The relationship of interleukin-1 and immune functions to sleep in humans. Psychosom. Med. 48, 309-318 (1986).

40. Lue, F. A. et al. Sleep and cerebrospinal fluid interleukin-1-like activity in the cat. Int. J. Neurosci. 42, 179-183 (1988)

41. Opp, M. R. \& Toth, L. A. Neural-immune interactions in the regulation of sleep. Front. Biosci. 8 d768-d779 (2003).

42. Turrin, N. P. et al. Pro-inflammatory and antiinflammatory cytokine mRNA induction in the periphery and brain following intraperitoneal administration of bacterial lipopolysaccharide. Brain Res. Bull. 54, 443-453 (2001).

43. Zhang, Y., Gaekwad, J., Wolfert, M. A. \& Boons, G. J. Modulation of innate immune responses with synthetic lipid A derivatives. J. Am. Chem. Soc. 129 5200-5216 (2007).

44. Datta, S. C. \& Opp, M. R. Lipopolysaccharide-induced increases in cytokines in discrete mouse brain regions are detectable using Luminex xMAP technology. J. Neurosci. Methods 175, 119-124 (2008).

45. Krueger, J. M. \& Majde, J. A. Microbial products and cytokines in sleep and fever regulation. Crit. Rev. Immunol. 14, 355-379 (1994).

46. Imeri, L., Opp, M. R. \& Krueger, J. M. An IL-1 receptor and an IL-1 receptor antagonist attenuate muramyl dipeptide- and IL-1-induced sleep and fever. Am. J. Physiol. 265, R907-R913 (1993).

47. Dunn, A. J. Effects of cytokines and infections on brain neurochemistry. Clin. Neurosci. Res. 6, 52-68 (2006).

48. Brodie, B. B., Pletscher, A. \& Shore, P. A. Evidence that serotonin has a role in brain function. Science $\mathbf{1 2 2}$, 968 (1955).

49. Jacobs, B. L. \& Azmitia, E. C. Structure and function of the brain serotonin system. Physiol. Rev. 72 165-229 (1992).

50. Ursin, R. Serotonin and sleep. Sleep Med. Rev. 6 55-69 (2002)

51. Anisman, H., Merali, Z. \& Hayley, S. Neurotransmitter peptide and cytokine processes in relation to depressive disorder: comorbidity between depression and neurodegenerative disorders. Prog. Neurobiol. 85, 1-74 (2008)
52. Jouvet, M. Sleep and serotonin: an unfinished story. Neuropsychopharmacology 21, 24s-27s (1999). A historical review of $\mathbf{4 0}$ years of investigation into 5-HT's role in regulating arousal state by the investigator who is best known for his contributions to this topic. Data are interpreted within the framework of the hypothesis that 5-HT promotes wakefulness but stimulates the synthesis or release of unknown sleep factors that induce subsequent sleep.

53. Cespuglio, R., Gomez, M. E., Walker, E. \& Jouvet, M. Effets du refroidissement et de la stimulation des noyaux du systeme du raphe sur les etats de vigilance chez le chat. Electroenceph. Clin. Neurophysiol. 47, 289-308 (1979).

54. Cespuglio, R., Faradji, H., Gomez, M. E. \& Jouvet, M. Single unit recordings in the nuclei raphe dorsalis and magnus during sleep-waking cycle of semi-chronic prepared cats. Neurosci. Lett. 24, 133-138 (1981).

55. Lydic, R., McCarley, R. W. \& Hobson, J. A. Serotonin neurons and sleep. I. Long term recordings of dorsal raphe discharge frequency and PGO waves. Arch. Ital. Biol. 125, 317-343 (1987)

56. McGinty, D. J. \& Harper, R. M. Dorsal raphe neurons: depression of firing during sleep in cats. Brain Res. 101, 569-575 (1976)

This was the first study to demonstrate state-dependent activity of serotonergic neurons.

57. Trulson, M. E. \& Jacobs, B. L. Raphe unit activity in freely moving cats: correlation with level of behavioral arousal. Brain Res. 163, 135-150 (1979)

58. Cespuglio, R. et al. Voltammetric detection of the release of 5-hydroxyindole compounds throughout the sleep-waking cycle of the rat. Exp. Brain Res. 80, 121-128 (1990).

59. Gemma, C., Imeri, L., De Simoni, M. G. \& Mancia, M Interleukin-1 induces changes in sleep, brain temperature, and serotonergic metabolism. Am. J. Physiol. Regul. Integr. Comp. Physiol. 272, R601-R606 (1997)

60. Portas, C. M. \& McCarley, R. W. Behavioral staterelated changes of extracellular serotonin concentration in the dorsal raphe nucleus: microdialysis study in the freely moving cat. Brain Res. 648, 306-312 (1994)

61. Portas, C. M. et al. On-line detection of extracellular levels of serotonin in dorsal raphe nucleus and fronta cortex over the sleep/wake cycle in the freely moving rat. Neuroscience 83, 807-814 (1998).

62. Dugovic, C. Functional activity of $5-\mathrm{HT}_{2}$ receptors in the modulation of the sleep/wakefulness states. J. Sleep Res. 1, 163-168 (1992).

63. Saper, C. B., Chou, T. C. \& Scammell, T. E. The sleep switch: hypothalamic control of sleep and wakefulness. Trends Neurosci. 24, 726-731 (2001).

64. Jones, B. E. From waking to sleeping: neuronal and chemical substrates. Trends Pharmacol. Sci. 26 578-586 (2005)

65. Imeri, L., Mancia, M., Bianchi, M. \& Opp, M. R. 5-hydroxytryptophan, but not L-tryptophan, alters sleep and brain temperature in rats. Neuroscience 95 445-452 (2000).

The first of several papers by these authors to demonstrate that activation of the 5-HT system has a biphasic effect on arousal state, with initial wakefulness followed by subsequent NREM sleep.

66. Imeri, L., Bianchi, S. \& Opp, M. R. Antagonism of corticotropin-releasing hormone alters serotonergic induced changes in brain temperature, but not sleep, of rats. Am. J. Physiol. Regul. Integr. Comp. Physiol. 289, R1116-R1123 (2005).

67. Morrow, J. D., Vikraman, S., Imeri, L. \& Opp, M. R. Effects of serotonergic activation by 5-hydroxytryptophan on sleep and body temperature of C57BL/56J and interleukin-6-deficient mice are dose and time related. Sleep 31, 21-33 (2008).

68. McCarley, R. W. Neurobiology of REM and NREM sleep. Sleep Med. 8, 302-330 (2007).

69. Lu, J., Sherman, D., Devor, M. \& Saper, C. B. A putative flip-flop switch for control of REM sleep. Nature 441, 589-594 (2006).

70. Adrien, J., Alexandre, C., Boutrel, B. \& Popa, D. Contribution of the "knock-out" technology to understanding the role of serotonin in sleep regulations. Arch. Ital. Biol. 142, 369-377 (2004).

1. Hagan, J. J. et al. Characterization of SB-269970-A, a selective $5-\mathrm{HT}_{7}$ receptor antagonist. Br. J. Pharmacol. 130, 539-548 (2000)

72. Hedlund, P. B., Huitron-Resendiz, S., Henriksen, S. J. \& Sutcliffe, J. G. 5-HT receptor inhibition and inactivation induce antidepressantlike behavior and sleep pattern. Biol. Psychiatry 58, 831-837 (2005).

73. Obal, F. Jr \& Krueger, J. M. Biochemical regulation of non-rapid-eye-movement sleep. Front. Biosci. 8 , d520-d550 (2003).

74. Manfridi, A. et al. Interleukin-1 $\beta$ enhances non-rapid eye movement sleep when microinjected into the dorsal raphe nucleus and inhibits serotonergic neurons in vitro. Eur. J. Neurosci. 18, 1041-1049 (2003).

75. Brambilla, D., Franciosi, S., Opp, M. R. \& Imeri, L. Interleukin-1 inhibits firing of serotonergic neurons in the dorsal raphe nucleus and enhances GABAergic inhibitory post-synaptic potentials. Eur. J. Neurosci. 26, 1862-1869 (2007)

76. Serantes, R. et al. Interleukin- $1 \beta$ enhances GABA receptor cell-surface expression by a phosphatidylinositol 3-kinase/Akt pathway: relevance to sepsis-associated encephalopathy. J. Biol. Chem. 281, 14632-14643 (2006)

77. Miller, L. G., Galpern, W. R., Dunlap, K., Dinarello, C. A. \& Turner, T. J. Interleukin-1 augments gamma aminobutyric acid $_{\mathrm{A}}$ receptor function in brain. Mol. Pharmacol. 39, 105-108 (1991)

78. Tabarean, I. V., Korn, H. \& Bartfai, T. Interleukin-1 $\beta$ induces hyperpolarization and modulates synaptic inhibition in preoptic and anterior hypothalamic neurons. Neuroscience 141, 1685-1695 (2006).

79. Feleder, C., Arias, P., Refojo, D., Nacht, S. \& Moguilevsky, J. Interleukin-1 inhibits NMDAstimulated $\mathrm{GnRH}$ secretion: associated effects on the release of hypothalamic inhibitory amino acid neurotransmitters. Neuroimmunomodulation 7 46-50 (2000)

80. Zeise, M. L., Madamba, S. \& Siggins, G. R Interleukin- $1 \beta$ increases synaptic inhibition in rat hippocampal pyramidal neurons in vitro. Regul. Pept. 39, 1-7 (1992).

81. Luk, W. P. et al. Adenosine: a mediator of interleukin$1 \beta$-induced hippocampal synaptic inhibition. J. Neurosci. 19, 4238-4244 (1999).

82. Alam, M. N. et al. Interleukin- $1 \beta$ modulates statedependent discharge activity of preoptic area and basal forebrain neurons: role in sleep regulation. Eur. J. Neurosci. 20, 207-216 (2004).

These authors demonstrated for the first time that IL-1 applied directly to the hypothalamus inhibits wake-active neurons. The paper also reported increases in discharge rates in a subset of sleep-active neurons.

83. Baker, F. C. et al. Interleukin $1 \beta$ enhances non-rapid eye movement sleep and increases c-Fos protein expression in the median preoptic nucleus of the hypothalamus. Am. J. Physiol. Regul. Integr. Comp. Physiol. 288, R998-R1005 (2005).

84. Shintani, F et al Interleukin- $1 \beta$ augments release of norepinephrine, dopamine, and serotonin in the rat anterior hypothalamus. J. Neurosci. 13, 3574-3581 (1993).

85. Denoyer, M., Sallanon, M., Kitahama, K., Aubert, C. \& Jouvet, M. Reversibility of

para-chlorophenylalanine-induced insomnia by intrahypothalamic microinjection of

L-5-hydroxytryptophan. Neuroscience 28, 83-94 (1989).

These authors demonstrated that the anterior hypothalamus is the only brain region where 5-HTP rescues sleep in cats made insomniac by depletion of brain 5-HT.

86. Khateb, A., Fort, P., Alonso, A., Jones, B. E. \& Muhlethaler, M. Pharmacological and immunohistochemical evidence for serotonergic modulation of cholinergic nucleus basalis neurons. Eur. J. Neurosci. 5, 541-547 (1993).

87. Imeri, L., Bianchi, S. \& Mancia, M. Muramyl dipeptide and IL-1 effects on sleep and brain temperature after inhibition of serotonin synthesis. Am. J. Physiol. Regul. Integr. Comp. Physiol. 273, R1663-R1668 (1997).

88. Imeri, L., Mancia, M. \& Opp, M. R. Blockade of 5-HT receptors alters interleukin-1-induced changes in rat sleep. Neuroscience 92, 745-749 (1999).

89. Gemma, C., Imeri, L. \& Opp, M. R. Serotonergic activation stimulates the pituitary-adrenal axis and alters interleukin-1 mRNA expression in rat brain Psychoneuroendocrinology 28, 875-884 (2003) This was the first paper to report that activation of the serotonergic system alters IL-1 mRNA expression in the brain

90. Dinarello, C. A. et al. Interleukin 1 induces interleukin 1. I. Induction of circulating interleukin 1 in rabbits in vivo and in human mononuclear cells in vitro. J. Immunol. 139, 1902-1910 (1987). 
91. Taishi, P., Churchill, L., De, A., Obal, F. Jr \& Krueger, J. M. Cytokine mRNA induction by interleukin- $1 \beta$ or tumor necrosis factor a in vitro and in vivo. Brain Res. 1226, 89-98 (2008)

92. Turnbull, A. V. \& Rivier, C. Regulation of the hypothalamic-pituitary-adrenal axis by cytokines: actions and mechanisms of action. Physiol. Rev. 79 , 1-71 (1999).

93. Mignot, E. Why we sleep: the temporal organization of recovery. PLoS Biol. 6, e106 (2008).

94. Siegel, J. M. Clues to the functions of mammalian sleep. Nature 437, 1264-1271 (2005).

95. Toth, L. A., Tolley, E. A. \& Krueger, J. M. Sleep as a prognostic indicator during infectious disease in rabbits. Proc. Soc. Exp. Biol. Med. 203, 179-192 (1993).

This retrospective analysis of data derived from almost 100 rabbits revealed associations between the quality of sleep and clinical symptoms, morbidity and mortality. Survival from infectious pathogens is associated with better quality sleep.

96. Parmeggiani, P. L. Thermoregulation and sleep. Front Biosci. 8, s557-s567 (2003).

97 Kluger, M. J., Kozak, W. Conn, C. A , Leon, L. R. \& Soszynski, D. The adaptive value of fever. Infect. Dis. Clin. North Am. 10, 1-21 (1996).

98. Obăl, F. Jr, Rubicsek, G., Sary, G. \& Obál, F. Changes in the brain and core temperatures in relation to the various arousal states in rats in the light and dark periods of the day. Pflügers Arch. 404, 73-79 (1985).

99. Glotzbach, S. F. \& Heller, H. C. Central nervous regulation of body temperature during sleep. Science 194, 537-538 (1976).

100. Kluger, M. J. Fever. It's Biology, Evolution and Function (Princeton Univ. Press, Princeton, 1979).

101. Pollmacher, T. et al. Experimental immunomodulation sleep, and sleepiness in humans. Ann. NY Acad. SCi. 917, 488-499 (2000).

102. Mullington, J. et al. Dose-dependent effects of endotoxin on human sleep. Am. J. Physiol. 278, R947-R955 (2000).

103. Haack, M., Schuld, A., Kraus, T. \& Pollmacher, T. Effects of sleep on endotoxin-induced host responses in healthy men. Psychosom. Med. 63, 568-578 (2001).

Along with references 101 and 102, this paper demonstrated the effects on the sleep of healthy human volunteers of host defence activation by injection of endotoxin.

104. Friess, E., Wiedemann, K., Steiger, A. \& Holsboer, F. The hypothalamic-pituitary-adrenocortical system and sleep in man. Adv. Neuroimmunol. 5, 111-125 (1995).

105. Steiger, A. Sleep and the hypothalamo-pituitary-adrenocortical system. Sleep Med. Rev. 6, 125-138 (2002)

106. Palmblad, J., Pertrini, B., Wasserman, J. \& Kerstedt, T. A. Lymphocyte and granulocyte reactions during sleep deprivation. Psychosom. Med. 41, 273-278 (1979).

The first study of human subjects to specifically focus on the impact of sleep loss on immunity.
107. Dinges, D. F. et al. Leukocytosis and natural killer cell function parallel neurobehavioral fatigue induced by 64 hours of sleep deprivation. J. Clin. Invest. 93 1930-1939 (1994)

108. Irwin, M. R., Wang, M., Campomayor, C. O., ColladoHidalgo, A. \& Cole, S. Sleep deprivation and activation of morning levels of cellular and genomic markers of inflammation. Arch. Intern. Med. 166, 1756-1762 (2006).

109. Marshall, L. \& Born, J. Brain-immune interactions in sleep. Int. Rev. Neurobiol. 52, 93-131 (2002).

110. Rada, P. et al. Interleukin-1 $\beta$ decreases acetylcholine measured by microdialysis in the hippocampus of freely moving rats. Brain Res. 550, 287-290 (1991).

111. Carmeliet, P., Van Damme, J. \& Denef, C. Interleukin-1 beta inhibits acetylcholine synthesis in the pituitary corticotropic cell line AtT20. Brain Res. 491, 199-203 (1989).

112. Li, Y. et al. Neuronal-glial interactions mediated by interleukin-1 enhance neuronal acetylcholinesterase activity and mRNA expression. J. Neurosci. $\mathbf{2 0}$ $1-149$ (2000).

113. Fogal, B. \& Hewett, S. J. Interleukin-1 $\beta$ : a bridge between inflammation and excitotoxicity? J. Neurochem. 106, 1-23 (2008).

114. Basheer, R., Strecker, R. E., Thakkar, M. M. \& McCarley, R. W. Adenosine and sleep-wake regulation. Prog. Neurobiol. 73, 379-396 (2004)

115. Sperlagh, B., Baranyi, M., Hasko, G. \& Vizi, E. S Potent effect of interleukin- $1 \beta$ to evoke ATP and adenosine release from rat hippocampal slices. J. Neuroimmunol. 151, 33-39 (2004).

116. Zhu, G. et al. Involvement of $\mathrm{Ca}^{2+}$-induced $\mathrm{Ca}^{2+}$ releasing system in interleukin- $1 \beta$-associated adenosine release. Eur. J. Pharmacol. 532, 246-252 (2006).

117. Rosenbaum, E. Warum müssen wir schlafen? Eine neue Theorie des Schlafes (August Hirschwald, Berlin, 1892)

118. Tigerstedt, R. \& Bergman, P. Niere und kreislauf. Arch Physiol. 8, 223-271 (1898).

119. Baylis, W. \& Starling, E. The mechanism of pancreatic secretion. J. Physiol. 28, 325-353 (1902).

120. Ishimori, K. True cause of sleep: a hypnogenic substance as evidenced in the brain of sleep-deprived animals. Tokyo Igakkai Zasshi 23, 429-459 (1909).

121. Legendre, R. \& Piēron, H. Recherches sur le besoin de sommeil consecutif a une vielle prolongee. Z. Allg. Physiol. 14, 235-262 (1913).

122. Kornmüller, A., Lux, H., Winkel, K. \& Klee, M. Neurohumoral ausgelöste schlafzustände an tieren mit gekreuztem kreislfau unter kontrolle von EEGableitungen. Naturwissenschaften 14, 503-505 (1961)

123. Schoenenberger, G. A., Maier, P. F., Tobler, H. J. \& Monnier, M. A naturally occuring delta-EEG enhancing nonapeptide in rabbits. Pflügers Arch. 369, 99-109 (1977).

124. Nagasaki, H., Iriki, M., Inoue, S. \& Uchizono, K. Proceedings: Sleep promoting substances in the brain stem of rats. Nippon Seirigaku Zasshi 36, 293 (1974).

125. Pappenheimer, J. R., Miller, T. B. \& Goodrich, C. A. Sleep-promoting effects of cerebrospinal fluid from sleep-deprived goats. Proc. Natl Acad. Sci. USA 58, 513-517 (1967).
126. Fencl, V., Koski, G. \& Pappenheimer, J. R. Factors in cerebrospinal fluid from goats that affect sleep and activity in rats. J. Physiol. 216, 565-589 (1971).

127. Pappenheimer, J. R., Koski, G., Fencl, V., Karnovsky, M. L. \& Krueger, J. Extraction of sleep-promoting factor $\mathrm{S}$ from cerebrospinal fluid and from brains of sleep-deprived animals. J. Neurophysiol. 38, 1299-1311 (1975).

128. Krueger, J. M., Pappenheimer, J. R. \& Karnovsky, M. L. Sleep-promoting factor S: purification and properties. Proc. Natl Acad. Sci. USA 75, 5235-5238 (1978).

129. Krueger, J. M., Pappenheimer, J. R. \& Karnovsky, M. L. The composition of sleep-promoting factor isolated from human urine. J. Biol. Chem. 257 1664-1669 (1982).

130. Krueger, J. M., Pappenheimer, J. R. \& Karnovsky, M. L. Sleep-promoting effects of muramyl peptides. Proc. Natl Acad. Sci. USA 79, 6102-6106 (1982).

131. Fontana, A., Kristensen, F., Dubs, R., Gemsa, D. \& Weber, E. Production of prostaglandin E and an interleukin-1 like factor by cultured astrocytes and C glioma cells. J. Immunol. 129, 2413-2419 (1982).

132. Krueger, J. M., Dinarello, C. A. \& Chedid, L. Promotion of slow-wave sleep (SWS) by a purified interleukin-1 (IL-1) preparation. Fed. Proc. 42, 356 (1983).

133. Krueger, J. M., Walter, J., Dinarello, C. A., Wolff, S. M $\S$ Chedid, L. Sleep-promoting effects of endogenous pyrogen (interleukin-1). Am. J. Physiol. 246, R994-R999 (1984).

This and reference 134 were the first research articles to demonstrate the effects of IL-1 on sleep and the electroencephalogram.

134. Tobler, I., Borbély, A. A., Schwyzer, M. \& Fontana, A Interleukin-1 derived from astrocytes enhances slow wave activity in sleep EEG of the rat. Eur. J. Pharmacol. 104, 191-192 (1984).

135. Shoham, S., Davenne, D., Cady, A. B., Dinarello, C. A \& Krueger, J. M. Recombinant tumor necrosis factor and interleukin 1 enhance slow-wave sleep. Am. J. Physiol. 253, R142-R149 (1987).

Acknowledgements

The authors were supported by US National Institutes of Health Grants MH64843 and HL080972, the Department of Anesthesiology of the University of Michigan Medical School, and the Ministero dell'Istruzione, dell'Universita'e della Ricerca, Italy.

DATABASES

Entrez Gene: http://www.ncbi.nlm.nih.gov/entrez/query. fcgi? db=gene IL-1 ITNF

\section{FURTHER INFORMATION}

Luca Imeri's homepage: http://users.unimi.it/imeri/ Mark R. Opp's homepage: http://www.med.umich.edu/ anesresearch/opp.htm ALL LINKS ARE ACTIVE IN THE ONLINE PDF 